\title{
IMPLEMENTATION OF ACADEMIC SUPERVISION MANAGEMENT IN PRIMARY SCHOOL TO FACE THE DISRUPTION ERA
}

\section{Desi Ratnasari, Roemintoyo, Winarno}

Universitas Sebelas Maret

deade.ratna@gmail.com

\section{Article History}

accepted 09/07/2018

approved 01/08/2018

published 17/09/2018

\section{Keywords}

Implementation,

management, academic

supervision,

\begin{abstract}
Supervision is part of school-based management. The implementation of supervision, especially in the field of academics is very important to see the shortcomings of the implementation of learning, in order to always try to improve the quality of education. The purpose of this study to explain the implementation of supervision in primary schools. This study uses descriptive-qualitative research methods. Principals conduct academic supervision of teachers every month. Principals always give feedback to teachers after seeing the implementation of learning to always improve the quality of education. Academic supervision on the performance of teachers in the learning process is very important for teachers to always innovate in the implementation of learning to improve the quality of education in the face of disruption era.
\end{abstract}

Social, Humanities, and Education Studies (SHEs): Conference Series https://jurnal.uns.ac.id/shes
p-ISSN 2620-9284

e-ISSN 2620-9292 


\section{PENDAHULUAN}

Dalam perkembangannya, pengawas satuan pendidikan lebih diarahkan untuk memiliki serta memahami bahkan dituntut untuk dapat mengamalkan apa yang tertuang dalam peraturan menteri tentang kepengawasan. Tuntutan tersebut salah satunya tentang kompetensi dalam memahami metode dan teknik dalam supervisi. Seorang supervisor adalah orang yang profesional ketika menjalankan tugasnya, ia bertindak atas dasar kaidah-kaidah ilmiah untuk meningkatkan mutu pendidikan. Untuk menjalankan supervisi diperlukan kelebihan yang dapat melihat dengan tajam terhadap permasalahan dalam peningkatan mutu pendidikan, menggunakan kepekaan untuk memahaminya dan tidak hanya sekedar menggunakan penglihatan mata biasa, sebab yang diamatinya bukan masalah kongkrit yang tampak, melainkan memerlukan insight dan kepekaan mata batin.

Seorang supervisor membina peningkatan mutu akademik yang berhubungan dengan usaha-usaha menciptakan kondisi belajar yang lebih baik berupa aspek akademis, bukan masalah fisik material semata. Ketika supervisi dihadapkan pada kinerja dan pengawasan mutu pendidikan oleh pengawas satuan pendidikan, tentu memiliki misi yang berbeda dengan supervisi oleh kepala sekolah. Hal ini bertujuan untuk memberikan pelayanan kepada kepala sekolah dalam mengembangkan mutu kelembagaan pendidikan dan memfasilitasi kepala sekolah agar dapat melakukan pengelolaan kelembagaan secara efektif dan efisien.

Mulyasa (2017:156) berpendapat bahwa "Supervisi mengandung beberapa kegiatan pokok, yaitu pembinaan yang kontinu, pengembangan kemampuan professional personil, perbaikan situasi belajar-mengajar, dengan sasaran akhir pencapaian tujuan pendidikan dan pertumbuhan pribadi peserta didik". Supervisi merupakan sebuah kegiatan pembinaan yang berkelanjutan dengan tujuan memperbaiki situasi belajar mengajar untuk meningkatkan mutu pendidikan. Pendapat tersebut didukung oleh pernyataan Sutomo yang sependapat bahwa (2012:99) "Supervisi bukanlah kegiatan sesaat seperti inspeksi, tetapi merupakan kegiatan yang kontinu dan berkesinambungan sehingga guru-guru selalu berkembang dalam mengerjakan tugas dan mampu memecahkan berbagai masalah pendidikan dan pengajaran secara efektif dan efisien". Dengan demikian, kegiatan supervisi harus dilakukan dengan rutin agar terus ada perbaikan dalam dunia pendidikan.

Leniwati dan Yasir (2017:107) menjelaskan bahwa "Tujuan supervisi adalah membantu guru mengembangkan kemampuannya mencapai tujuan pembelajaran yang harus dicapai peserta didik. yaitu dengan peningkatan pengetahuan dan keterampilan guru mengajar, peningkatan komitmen (commitment), dan kemauan (willingness) serta motivasi (motivation) guru, sebab dengan meningkatkan kemampuan dan motivasi kerja guru, kualitas pembelajaran akan lebih meningkat". Tujuan supervisi yang utama adalah untuk membangtu guru mengembangkan kemampuan dan kreativitas dalam mencapai tujuan pembelajaran.

Tujuan supervisi menurut Suto Prabowo dkk (2016:99) ialah : 1) Tujuan akhir adalah untuk mencapai pertumbuhan dan perkembangan para siswa (yang bersifat total). Dengan demikian sekaligus akan dapat memperbaiki masyarakat. 2) Tujuan kedua adalah membantu kepala sekolah dalam menyesuaikan program pendidikan dari waktu ke waktu secara kontinu dalam rangka menghadapi tatntangan perubahan zaman. 3) Tujuan dekat adalah bekerjasama mengembangkan proses belajar mengajar yang tepat. 4) Tujuan perantaraan adalah membina guru-guru agar dapat mendidik para siswa dengan baik, atau menegakkan disiplin kerja secara manusiawi.

Secara garis besar, tujuan dari supervisi adalah saling membina dan meningkatkan kualitas pendidikan dengan cara mengembangkan kreatifitas dalam proses pembelajaran. 
Berdasarkan hasil observasi awal di sekolah, ditemukan beberapa fakta bahwa supervisi di sekolah belum bisa berjalan maksimal. Supervisi yang dilakukan kepala sekolah kepada guru hanya 2 kali dalam satu tahun.

Berdasarkan fakta di atas, maka bantuan berupa pengawasan profesional oleh pengawas satuan tenaga kependidikan tentunya diarahkan pada upaya untuk meningkatkan pelaksanaan kegiatan kepala sekolah dalam menetralisir, mengidentifikasi serta menemukan peluang-peluang yang dapat diciptakan guna meningkatkan mutu kelembagaan secara menyeluruh. Supervisi akademik sangat penting guna mengevaluasi kinerja guru dalam proses pembelajaran, dikarenakan guru merupakan ujung tombak dari kualitas pendidikan. Namun tidak hanya itu, supervisi juga diperlukan untuk meningkatkan kreatifitas guru dalam menghadapi era disrupsi. Rumusan dari artikel ini yaitu bagaimana implementasi supervisi akademik di Sekolah Dasar? Dengan tujuan untuk mengetahui implementasi supervisi akademik di Sekolah Dasar.

\section{METODE}

Kajian ini menggunakan mwtode penelitian deskriptif-kualitatif, yaitu prosedur penelitian yang menghasilkan data deskriptif berupa kata-kata tertulis atau lisan dari responden atau orang-orang yang perilakunya diamati (Cut Suryani, 2015:25). Penelitian ini mendeskripsikan berbagai hal yang berkaitan dengan fokus permasalahan yang diangkat. Data dikumpulkan melalui observasi dan wawancara.

Penelitian ini dilakukan di SD Negeri 02 Jetis Kecamatan Jaten Kabupaten Karanganyar dengan melibatkan kepala sekolah dan guru sebagai sumber utama dalam penelitian. Waktu penelitian dilaksanakan pada hari senin tanggal 28 Mei 2018 pada jam dinas sekolah jam 08.00-10.00.

\section{HASIL DAN PEMBAHASAN}

Berdasarkan hasil wawancara dengan Kepala Sekolah SD Negeri 02 Jetis Kecamatan Jaten Kabupaten Karanganyar, ditemukan beberapa fakta dilapangan yaitu:

1. sekolah tersebut telah melaksanakan supervisi akademik.

2. semua guru terlibat dalam penyusunan program dan jadwal supervisi.

3. kepala sekolah memberikan penghargaan kepada guru berupa motivasi.

4. kepala sekolah memantau kinerja guru dalam proses pembelajaran dengan cara melihat langsung pelaksanaan pembelajaran di kelas.

5. kepala sekolah melakukan penilaian terhadap guru dalam proses pembelajaran dengan melihat kesesuaian RPP dengan pelaksanaan pembelajaran, kreatifitas guru dalam pelaksanaan pembelajaran, kelengkapan administrasi.

6. bentuk tindak lanjut dari kepala sekolah yaitu:

a. pemberian contoh proses pembelajaran yang sesuai

b. pelaksanaan pelatihan terhadap guru

c. pelaksanaan diskusi terhadap proses pembelajaran yang sesuai

d. pemberian layanan konsultasi proses pembelajaran

e. peringatan kepada guru yang menunjukkan kinerja kurang memenuhi

f. pemberian kesempatan kepada guru untuk mengikuti pelatihan

7. guru terlibat sebagai subyek dalam pelaksanaan program supervisi akademik

8. supervisi dari kepala sekolah kepada guru dilaksanakan 6 kali dalam 1 semester.

9. administrasi yang harus dikerjakan oleh guru dalam pelaksanaan supervisi berdasarkan standar proses yaitu:
a. program tahunan

b. program semester 
c. silabus pembelajaran

d. rencana pelaksanaan pembelajaran (RPP)

e. kalender pendidikan

f. jadwal pelajaran

g. rencana harian/ jurnal pembelajaran

h. buku penilaian

i. KKM

j. Analisis materi pelajaran

k. buku siswa dan pegangan guru

I. program pelaksanaan bimbingan dan penyuluhan

m. program pelaksanaan kegiatan ekstrakurikuler

10. ada bimbingan dan pengarahan dari kepala sekolah terhadap guru dalam pelaksanaan administrasi akademik.

\section{SIMPULAN}

SDN 02 Jetis telah melaksanakan supervisi akademik. Semua guru terlibat dalam penyusunan program dan jadwal supervisi. Kepala sekolah memberikan penghargaan kepada guru berupa motivasi. Kepala sekolah memantau kinerja guru dalam proses pembelajaran dengan cara melihat langsung pelaksanaan pembelajaran di kelas. Kepala sekolah melakukan penilaian terhadap guru dalam proses pembelajaran dengan melihat kesesuaian RPP dengan pelaksanaan pembelajaran, kreatifitas guru dalam pelaksanaan pembelajaran, kelengkapan administrasi. Guru terlibat sebagai subyek dalam pelaksanaan program supervisi akademik Supervisi dari kepala sekolah kepada guru dilaksanakan 6 kali dalam 1 semester. Administrasi yang harus dikerjakan oleh guru dalam pelaksanaan supervisi berdasarkan standar proses yaitu: a. program tahunan, b. program semester, c. silabus pembelajaran, d. rencana pelaksanaan pembelajaran (RPP), e. kalender pendidikan, f. jadwal pelajaran, g. rencana harian/ jurnal pembelajaran, h. buku penilaian, i. KKM, j. Analisis materi pelajaran, k. buku siswa dan pegangan guru, l. program pelaksanaan bimbingan dan penyuluhan, $\mathrm{m}$. program pelaksanaan kegiatan ekstrakurikuler Ada bimbingan dan pengarahan dari kepala sekolah terhadap guru dalam pelaksanaan administrasi akademik. Bentuk tindak lanjut dari kepala sekolah yaitu: a. pemberian contoh proses pembelajaran yang sesuai, b. pelaksanaan pelatihan terhadap guru, c. pelaksanaan diskusi terhadap proses pembelajaran yang sesuai, $d$. pemberian layanan konsultasi proses pembelajaran, e. peringatan kepada guru yang menunjukkan kinerja kurang memenuhi, f. pemberian kesempatan kepada guru untuk mengikuti pelatihan.

\section{Buku}

\section{DAFTAR PUSTAKA}

Daryanto, 2013. Konsep Dasar Manajemen Pendidikan di Sekolah. Yogyakarta: Gava Media.

Made Pidarta. 2011. Manajemen Pendidikan Indonesia. Jakarta: Rineka cipta.

Mulyasa. 2012. Manajemen \& Kepemimpinan Kepala Sekolah. Jakarta: Bumi aksara.

Sutomo. 2012. Manajemen sekolah. Semarang: Unnes Press.

Tim Dosen UPI. 2009. Manajemen Pendidikan. Bandung: Alfabeta.

Jurnal

Leniwati, Yasir. 2017. Implementasi Supervisi Akademik Kepala Sekolah Untuk Meningkatkan Kinerja Guru. Jurnal Manajemen, Kepemimpinan, Dan Supervisi Pendidikan. Volume 2, No. 1, Januari-Juni 2017 
Nur'aini dkk. 2016. Implementasi Supervisi Akademik Kepala Mis Batusangkar. Jurnal Manajemen, Kepemimpinan, dan Supervisi Pendidikan. Volume 1, No. 2, JuliDesember 2016

Prabowo, Suta dkk. 2016. Supervisi Kunjungan Kelas Sebagai Upaya Membina Profesional Guru Sltp/Slta. Jurnal Sosial Humaniora, Vol 9 No.1, Juni 2016

Slameto. 2016. Supervisi Pendidikan oleh Pengawas Sekolah. Jurnal Manajemen Pendidikan. Volume: 3, No. 2, Juli-Desember 2016

Suryani, Cut. 2015. Implementasi Supervisi Pendidikan Dalam Meningkatkan Proses Pembelajaran Di Min Sukadamai Kota Banda Aceh. VOL. 16, NO. 1, 23-42

Sutarjo. 2014. Supervisi Pengawas Dan Kepala Sekolah Dalam Peningkatan Mutu Pembelajaran. Jurnal Pendidikan Unsika. Volume 2 Nomor 1, November 2014 